\title{
Synthesis and characterization of biomimetic hydroxyapatite/sepiolite nanocomposites $\dagger$
}

\author{
Chaoying Wan and Biqiong Chen*
}

\author{
Received 4th September 2010, Accepted 19th October 2010 \\ DOI: 10.1039/c0nr00650e
}

\begin{abstract}
Natural fibrous sepiolite with a high surface area, negative surface charge and porous structure is promising for hydroxyapatite (HAp) mineralization since the clay is naturally abundant and biocompatible. In this paper, the use of fibrous sepiolite as a template for growth of HAp nanocrystals was reported for the first time. Carbonated HAp nanorods with dimensions of 20-60 nm in length and $10-20 \mathrm{~nm}$ in diameter were successfully grown on the sepiolite surface with a preferred orientation to the $c$-axis. The critical nucleus radius of HAp in the presence of natural sepiolite was estimated as $0.296-0.312 \mathrm{~nm}$. Strong acid-activation increased the specific surface area of the sepiolite by $205 \%$ and also transformed the sepiolite to silica fiber with an elastic modulus being $395 \%$ of the original value. The novel HAp/acid-activated sepiolite biocomposite has a specific surface area of $182 \mathrm{~m}^{2} \mathrm{~g}^{-1}$ and an elastic modulus of over $20 \mathrm{GPa}$, considerably higher than those of the HAp synthesized without sepiolite. Such hierarchically assembled HAp/sepiolite biocomposites with controlled size and improved modulus open a new way to expand the applications of naturally abundant clays in biological load-bearing devices.
\end{abstract}

\section{Introduction}

Nanosized crystalline calcium phosphates in the form of apatites naturally occur as the basic inorganic contents of bones and teeth of mammals as a result of natural selection. ${ }^{1}$ Due to their large specific surface area, these apatites have strong interactions with proteins which are the major organic constituents in bones. ${ }^{2}$ The biological hydroxyapatite $\left(\mathrm{Ca}_{10}\left(\mathrm{PO}_{4}\right)_{6}(\mathrm{OH})_{2}, \mathrm{HAp}\right)$ exists as homogeneous plate-like nanocrystals with the size of $15-30 \mathrm{~nm}$ wide and $30-50 \mathrm{~nm}$ long in bones, and as rod-like nanocrystals of 25-100 nm thick with lengths in the range of $100 \mathrm{~nm}$ to several microns in enamel. ${ }^{3}$ Taking the inspiration from the natural tissues, synthesis of HAp nanocrystals with well-controlled sizes and shapes is regarded as an important prerequisite for biomineralization and biomimetic assembly of biocomposites. ${ }^{1,4 a}$ Compared to their microscaled counterparts, nanosized hydroxyapatites exhibit improved sinterability and densification, better bioactivity, superior biocompatibility and osteointegration of bone graft substitutes, ${ }^{4}$ and hence much enhanced performances because of their larger surface-to-volume ratios and unusual chemical synergistic effects.

The particle size and crystallinity of HAp are generally influenced by the presence of organic modifiers and reaction conditions. ${ }^{4}$ For example, spherical HAp nanoparticles with diameters of $20 \pm 5 \mathrm{~nm}, 40 \pm 10 \mathrm{~nm}$ and $80 \pm 12 \mathrm{~nm}$ were formed by varying the surfactant (hexadecyltrimethylammonium bromide)

Department of Mechanical and Manufacturing Engineering, Trinity Centre for Bioengineering, Trinity College Dublin, College Green, Dublin 2, Ireland. E-mail: chenb@tcd.ie; Fax: +3531679 5554; Tel: +3531896 1729

$\dagger$ Electronic supplementary information (ESI) available: XRF results of sepiolite and related biocomposites (Table S1), derivative thermogravimetry curves of HAp/sepiolite biocomposites (Fig. S1), and load-displacement curves of nanoindentation for various samples sintered at $1200{ }^{\circ} \mathrm{C}$ (Fig. S2). See DOI: $10.1039 / \mathrm{c} 0 \mathrm{nr} 00650 \mathrm{e}$ concentration in the range of $6.0 \times 10^{-4}$ to $12.0 \times 10^{-4} \mathrm{M} .{ }^{4 b} \mathrm{HAp}$ nanorods with dimensions from $\Phi 12.4 \mathrm{~nm} \times 30.0 \mathrm{~nm}$ to $\Phi$ $17.9 \mathrm{~nm} \times 48.7 \mathrm{~nm}$ were obtained by using different types of surfactants, and the crystallinity increased with the increasing synthesis temperatures. ${ }^{5}$ Microemulsion, micelle and reverse micelles, polymer capsules, Langmuir-Blodgett films and selfassembled monolayers ${ }^{1,4 b, c}$ provide confined environment for synthesis of HAp nanocrystals, in which the morphology and size of HAp were mainly dependent on the 'nanoreactor' profile and reaction condition.

Nanoparticles, such as titanium nanotubes, ${ }^{6}$ carbon nanotubes, ${ }^{7}$ mesoporous silica ${ }^{8}$ and gold nanoparticles, ${ }^{9}$ have also been used as templates for mineralization of nanocrystalline HAp, in which their dimensions and physiochemical properties play a key role in regulation of HAp growth. ${ }^{6-9}$ The nucleation activity of HAp was enhanced when synthesized with nanostructured titanium nanotubes. ${ }^{6}{ }^{a}$ Carboxyl-functionalized multi-walled carbon nanotubes (MWNTs) $)^{7 c}$ and PEGylation of MWNTs ${ }^{7 d}$ have been used as matrices for HAp growth based on the potential of carboxylate ions to bind $\mathrm{Ca}^{2+}$ ions onto their surfaces. Silica bioceramics are capable of promoting apatite precipitation and have been used as prosthetic bone and dental implants. ${ }^{8 b}$ Porous bioglass ceramics induce nucleation of HAp nanocrystals inside the pores where the pore size is a main factor governing the nanocrystal growth. It was found that bone bonding occurred when the bioglass porosity resulted in surface areas greater than $80 \mathrm{~m}^{2} \mathrm{~g}^{-1}{ }^{8 c}$ that pore sizes less than $2 \mathrm{~nm}$ were not suitable for inducing HAp growth, ${ }^{8 d}$ and that the critical nucleation diameter of the $\mathrm{HAp}$ on $\mathrm{CaO}-\mathrm{SiO}_{2}$ substrate was above $2.7 \mathrm{~nm}$ but below $4.9 \mathrm{~nm} .{ }^{8 e}$ Macroporous $\mathrm{CaO}-4 \mathrm{SiO}_{2}$ bioglass with a pore diameter of about $400 \mathrm{~nm}$ could form a full layer of HAp covering the pores when it was soaked in simulated body fluid at $37{ }^{\circ} \mathrm{C} .{ }^{8 f}$ As a summary of the above research, negatively charged and porous substrates are favorable for HAp mineralization. 

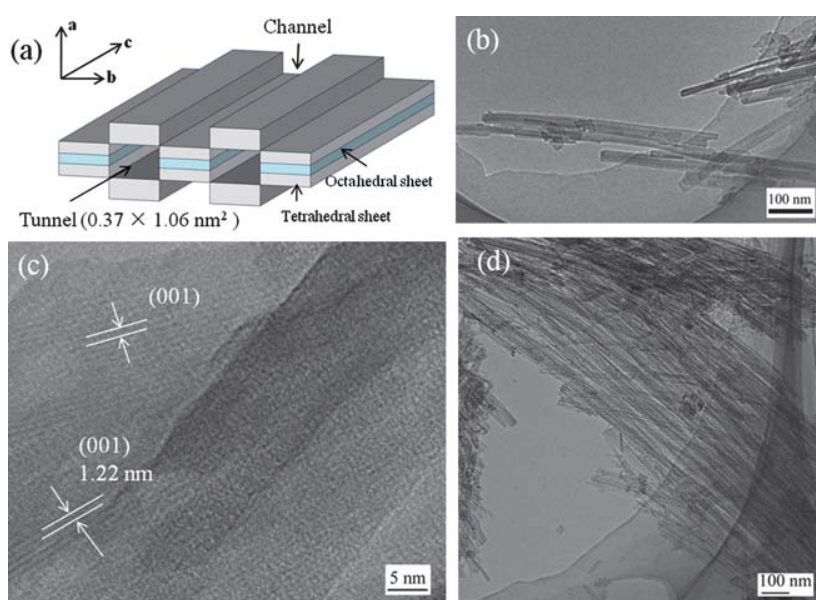

$5 \mathrm{~nm}$

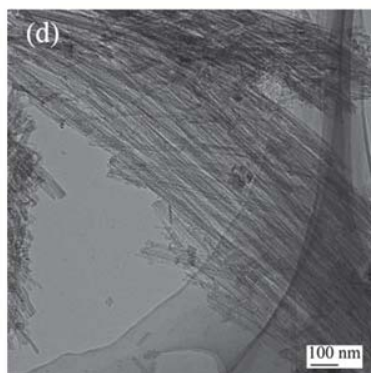

Fig. 1 TEM images illustrating the structures of the sepiolites before and after acid-activation: (a) scheme of sepiolite structure and dimensions; (b) the pristine sepiolite; (c) the high magnification image of the sepiolite showing $1.22 \mathrm{~nm}$ lattice-fringe separations; and (d) Acid-SEP2.

As an alternative nanoparticle template, natural fibrous sepiolite nanoclay, $\left(\mathrm{Si}_{12}\right)\left(\mathrm{Mg}_{8}\right) \mathrm{O}_{30}(\mathrm{OH})_{4}\left(\mathrm{OH}_{2}\right)_{48} \cdot \mathrm{H}_{2} \mathrm{O}$, with periodic structural intervals along the $b$-axis and micropore tunnels of dimensions of $0.37 \times 1.06 \mathrm{~nm}^{2}$ (ref. 10b) along the $c$-axis (Fig. 1a and b) providing a high specific surface area up to $320 \mathrm{~m}^{2} \mathrm{~g}^{-1}$, a porous volume of $0.4 \mathrm{~cm}^{3} \mathrm{~g}^{-1}{ }^{10 a}$ and a negative surface charge may accomplish the structural requirements for growing HAp nanocrystals with controlled sizes. Meanwhile, the roles of the nanometric tunnels and pore defects $(2-20 \mathrm{~nm}$ in diameter) ${ }^{10 c}$ in sepiolite structures in the HAp mineralization are highly in need of elucidation. Furthermore, acid-activated sepiolites owning higher porosity due to the acid-extraction of magnesium ions from the octahedral sheets ${ }^{10 d}$ and abundant silanol groups on the surface ${ }^{10 e}$ make them more promising to induce HAp biomineralization.

Clay minerals have widely been applied in pharmaceutical and biological applications due to their excellent properties such as high absorption/desorption capacity, ion exchange capacity, rheology, low or no toxicity and good biocompatibility. ${ }^{11}$ They have been proven to be effective inorganic hosts for proteins, drugs, bioactive molecules, and magnetic nanoparticles, ${ }^{12,13}$ etc. To the authors' knowledge, the use of clay for bioactive HAp mineralization has not been reported. In this paper, fibrous sepiolite was used as a template for in situ growth of HAp. The effects of physiochemical properties of the pristine sepiolite and two acid-activated sepiolites on the nucleation and morphology of HAp crystals were investigated. The resultant HAp/sepiolite biocomposites are expected to give better mechanical properties and similar bioactivity compared to HAp considering the high elastic modulus of acid-activated sepiolites and synergistic effects, which have great potential to be applied in polymerinorganic tissue scaffolds that often suffer the problems with low strength and modulus.

\section{Experimental}

\section{Materials}

A high purity sepiolite (Pansil S1500) supplied by Tolsa UK Ltd was used as received. The particle size was smaller than $5 \mu \mathrm{m}$ as determined by Field Emission Scanning Electron Microscopy. Hydrochloric acid $(\mathrm{HCl})$, calcium nitrate $\left(\mathrm{Ca}\left(\mathrm{NO}_{3}\right)_{2} \cdot 4 \mathrm{H}_{2} \mathrm{O}\right)$ and diammonium hydrogen phosphate $\left(\left(\mathrm{NH}_{4}\right)_{2} \mathrm{HPO}_{4}\right)$ were purchased from Sigma-Aldrich.

\section{Surface-modification of sepiolite}

Five grams of sepiolite clay were treated in $150 \mathrm{ml}$ of $1 \mathrm{M} \mathrm{HCl}$ at $100{ }^{\circ} \mathrm{C}$ under rigorous stirring for either $30 \mathrm{~min}$ or $3 \mathrm{~h}$ to produce different acid-activated sepiolites denoted as Acid-SEP1 and Acid-SEP2. Then, the acid-treated sepiolites were centrifuged and washed with distilled water for several times until the $\mathrm{pH}$ value of the final solution reached 7 . Finally they were oven-dried at $100{ }^{\circ} \mathrm{C}$ for $12 \mathrm{~h}$ and ground into fine powders.

\section{Mineralization using sepiolites}

HAp was synthesized by using the pristine sepiolite or Acid$\operatorname{SEP}(1,2)$ as a substrate, and the amounts of calcium and phosphate ions added for HAp formation were determined to give the final weight ratio of HAp to the substrate of $2: 1$. The aqueous sepiolite suspension of $1 \%(\mathrm{w} / \mathrm{v})$ was prepared and stirred at $50{ }^{\circ} \mathrm{C}$ overnight. The calcium ions solution $(0.5 \mathrm{M})$ and phosphate ions solution $(0.3 \mathrm{M})$ were prepared separately and preadjusted to $\mathrm{pH}=10$ by use of an ammonium solution. The $\mathrm{Ca}^{2+}$ solution was added to the sepiolite suspension and kept stirring for $2 \mathrm{~h}$, which was followed by a dropwise addition of $\mathrm{PO}_{4}{ }^{3-}$ ions to give the stoichiometric $\mathrm{Ca}^{2+} / \mathrm{PO}_{4}{ }^{3-}$ ratio of 1.67 for $\mathrm{HAp}$ formation. The $\mathrm{pH}$ was maintained at 10 throughout the experiment. The resultant suspension was stirred at $50{ }^{\circ} \mathrm{C}$ for $24 \mathrm{~h}$ and aged for $48 \mathrm{~h}$ at room temperature. The samples named as HAp/SEP, HAp/Acid-SEP1, and HAp/Acid-SEP2 were washed repeatedly with distilled water and ethanol before freezedrying. HAp in the absence of the sepiolites was prepared in parallel for comparison.

\section{Characterization}

Transmission Electron Microscopy (TEM) images were recorded on a JEOL 2011 microscope operated at $200 \mathrm{kV}$. The freeze-dried particles were dispersed in ethanol and then deposited on carboncoated copper grids. X-Ray Diffraction (XRD) measurements were performed on a Phillips PW1720 power X-ray diffractometer equipped with a multichannel detector by use of a $\mathrm{Cu} \mathrm{K} \mathrm{K}_{\alpha 1}$ $(\lambda=0.15406 \mathrm{~nm})$ monochromatic X-ray beam. All the samples were measured within $2 \theta$ of $2-70^{\circ}$ with a scan rate of $1^{\circ}$ per min. The average crystallite size $\left(D_{\mathrm{p}}\right)$ of HAp was calculated based on Scherrer's equation ${ }^{14 a}$ using the (002) diffraction peak from the XRD pattern. The crystallinity $\left(X_{\mathrm{c}}\right)$ was calculated according to $\beta_{002}\left(X_{\mathrm{c}}\right)^{1 / 3}=K_{\mathrm{A}},{ }^{14 b}$ where $\beta_{002}$ is in degree and $K_{\mathrm{A}}$ is a constant, i.e. 0.24. X-Ray fluorescence (XRF) quantitative measurements were carried out using a sequential Siemens SRS3000 spectrometer with a $\mathrm{Rh}$-anode $\mathrm{X}$-ray tube $(75 \mu \mathrm{m}$ Be window), a $60 \mathrm{kV}$ generator and an eight-position crystal changer. Thermogravimetric analyses (TGA) were performed on a Perkin Elmer Pyrus 1 TGA under nitrogen atmosphere. The temperature range was from 30 to $900{ }^{\circ} \mathrm{C}$ with the heating rate of $10{ }^{\circ} \mathrm{C}$ $\mathrm{min}^{-1}$. The FT-IR spectra were recorded on a Perkin Elmer Spectrum One NTS analyzer (resolution $4 \mathrm{~cm}^{-1}$ ) at room temperature. The specific surface areas were measured by $\mathrm{N}_{2}$ 
adsorption-desorption isotherms using a fully automated micromeritics Tristar 3000 BET surface area analyzer. Prior to the analysis, the moisture adsorbed on the surface of the fine powders was eliminated by preheating the powders at $150{ }^{\circ} \mathrm{C}$ for $2 \mathrm{~h}$, and the samples were degassed at $250^{\circ} \mathrm{C}$ for $3 \mathrm{~h}$. Densities were determined by helium pycnometry using a MicroMeritics AccuPyc 1330 Pycnometer.

Nanoindentation experiments were carried out using an MTS nanoindenter XP (MTS Systems) with a load-control method. The indenter system was calibrated using a fused silica standard sample (measured modulus of $73 \mathrm{GPa}$ ). A Berkovich diamond indenter with a total included angle of $142.3^{\circ}$ and $50 \mathrm{~nm}$ nominal radius was used throughout the measurement. Indentation tests were conducted at a loading/unloading rate of $0.05 \mathrm{mN} \mathrm{s}^{-1}$, with a hold time of $30 \mathrm{~s}$ at a maximum load of $50 \mathrm{mN}$ to minimize the influence of creep on unloading. A drift rate of $0.05 \mathrm{~nm} \mathrm{~s}^{-1}$ was applied to account for thermal expansion or contraction occurred in the test specimen and/or the indenter. Loaddisplacement curves were recorded and ten indents were made on each sample. The samples were uniaxially pressed at 8 tons to form disks with $13 \mathrm{~mm}$ diameter and $3 \mathrm{~mm}$ thick dimensions, and then calcinated in a furnace at $1200^{\circ} \mathrm{C}$ for $2 \mathrm{~h}$ with a heating rate of $10{ }^{\circ} \mathrm{C} \mathrm{min}-1$. The elastic modulus and hardness were determined using the Oliver-Pharr method, ${ }^{15}$ as detailed below.

The hardness $H$ was calculated by dividing the maximum applied load, $P_{\max }$, by the contact area, $A$, that is, ${ }^{15 a}$

$$
H=\frac{P_{\max }}{A}
$$

where the contact area is a function of the penetration depth, $h$ and is determined according to $A(h)=24.5 h^{2}$, in which the constant of 24.5 was used assuming a Berkovich indenter has a perfect tip. ${ }^{15 a}$

The elastic modulus $E$ of the samples is obtained by the following equation:

$$
\frac{1}{E_{\mathrm{r}}}=\frac{1-\nu^{2}}{E}+\frac{1-\nu_{\mathrm{i}}^{2}}{E_{\mathrm{i}}}
$$

where $E_{\mathrm{r}}$ and $v$ are the reduced modulus and Poisson's ratio of the sample; $E_{\mathrm{i}}$ and $v_{\mathrm{i}}$ are the elastic modulus and Poisson's ratio of diamond indenter, $E_{\mathrm{i}}=1140 \mathrm{GPa}, v_{\mathrm{i}}=0.07$. The Poisson's ratio for sepiolite and HAp are $0.28^{16 a}$ and $0.25,{ }^{16 c}$ respectively.

$$
E_{\mathrm{r}}=\frac{\sqrt{\pi} \beta S}{2 \sqrt{A}}
$$

where the contact stiffness $S=\mathrm{d} P / \mathrm{d} h$ and is obtained from the slope of the initial unloading curve by considering the maximum load and the maximum depth of indentation, and $\beta$ is the shape constant depending on the geometry of the Berkovich indenter, which is $1.034 .^{15 b}$

\section{Results and discussion}

\section{Characterization of the pristine and acid-treated sepiolites}

FT-IR spectra of the pristine sepiolite and acid-activated sepiolites are shown in Fig. 2. In Fig. 2A (curve a), the absorption bands at $3762-3560 \mathrm{~cm}^{-1}$ are ascribed to the $\mathrm{OH}$ stretching vibration from $\mathrm{Mg}_{3} \mathrm{OH}$ units in the octahedral structure of sepiolite. ${ }^{17 a}$ Broad bands near 3370 and $3240 \mathrm{~cm}^{-1}$ are due to $\mathrm{H}-\mathrm{O}-\mathrm{H}$ vibrations of adsorbed water. The absorption bands in the range of 1300 and $500 \mathrm{~cm}^{-1}$ are mainly ascribed to $\mathrm{Si}-\mathrm{O}$ bonds in the tetrahedral sheet. The wide band centered at $974 \mathrm{~cm}^{-1}$ is due to $\mathrm{Si}-\mathrm{O}-\mathrm{Si}$ in-plane vibration. The absorption at $787 \mathrm{~cm}^{-1}$ is due to $\mathrm{OH}$ deformation vibration, ${ }^{17 b}$ and the bands at around 694 and $644 \mathrm{~cm}^{-1}$ are ascribed to the $\mathrm{Mg}_{3} \mathrm{OH}$ bending vibrations. ${ }^{17 c}$

For the Acid-SEP1 (Fig. 2A, curve b), the absorption bands at $3560-3620 \mathrm{~cm}^{-1}$ ascribed to the $\mathrm{Mg}-\mathrm{OH}$ groups disappeared but the band near $3762 \mathrm{~cm}^{-1}$ still existed. The $\mathrm{Si}-\mathrm{O}$ absorption bands including 1211, 1078, 1006, and $974 \mathrm{~cm}^{-1}$ in sepiolite changed their shapes, shifted or disappeared, and the bands at around 694 and $644 \mathrm{~cm}^{-1}$ with lower intensities were still observed in Fig. 2A. This indicates that part of the $\mathrm{Mg}-\mathrm{OH}$ bonds in the sepiolite was ruptured due to the acid attack. ${ }^{17 d}$

For the Acid-SEP2 sample (Fig. 2A, curve c), the characteristic absorption bands for $\mathrm{Mg}-\mathrm{OH}$ at around 3762, 694 and $644 \mathrm{~cm}^{-1}$
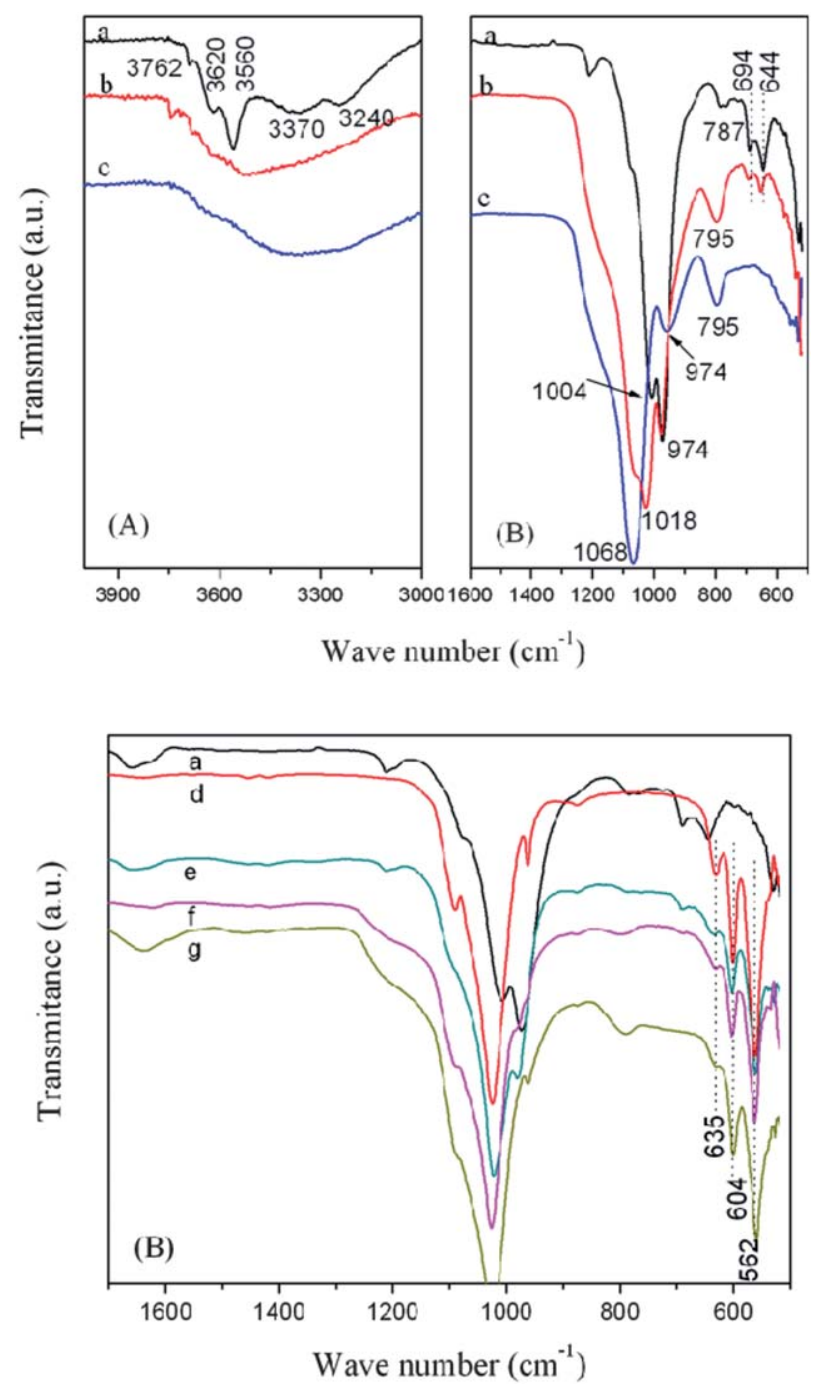

Fig. 2 FT-IR absorption spectra of the pristine sepiolite (a), Acid-SEP1 (b) and Acid-SEP2 (c) in the OH stretch and 1600-500 $\mathrm{cm}^{-1}$ regions (A); the spectra of the pristine sepiolite (a), HAp (d), HAp/SEP (e), HAp/ Acid-SEP1 (f), and HAp/Acid-SEP2 (g) biocomposites in $1600-500 \mathrm{~cm}^{-1}$ region $(\mathrm{B})$. 
disappeared indicating the absence of $\mathrm{Mg}-\mathrm{OH}$ in the octahedral sheet of Acid-SEP2 sample. The bands at 1057 and $1018 \mathrm{~cm}^{-1}$ combined into one peak and shifted to $1068 \mathrm{~cm}^{-1}$ which is associated to amorphous silica. ${ }^{17 e}$ Another characteristic band of amorphous silica near $795 \mathrm{~cm}^{-1}$ increased in intensity ${ }^{18 a}$ as the progress of acid dissolution. The changes of the $\mathrm{Si}-\mathrm{O}$ stretching band and the gradual movement to $1068 \mathrm{~cm}^{-1}$ indicate successive release of the $\mathrm{Mg}$ atoms from the octahedra as well as removal of $\mathrm{Mg}$ from the tetrahedral sheets. ${ }^{18 b}$

Fig. 3A shows the XRD patterns of the pristine and acidtreated sepiolites. The pristine sepiolite (curve a) displays an intense peak at $2 \theta=7.27^{\circ}(d$-spacing of $1.22 \mathrm{~nm})$, corresponding to the internal channel reflections, ${ }^{19}$ which is also observed by TEM (Fig. 1c). The diffraction peaks of sepiolite decreased in intensity during the mild acid-treatment as observed in AcidSEP1 (curve b). The disappearance of the characteristic peaks, especially the sharp peak at $2 \theta=7.27^{\circ}$, and appearance of a broad peak in the range of $15^{\circ}$ to $30^{\circ}$ associated to amorphous silica indicate that the crystalline structure of sepiolite collapses during the strong acid treatment. ${ }^{10}$ Along with the FT-IR characterization as discussed above and the XRF results presented in Table $\mathrm{S} 1 \uparrow$, this confirms that the magnesia layers have been completely removed from the sepiolite crystalline lattice
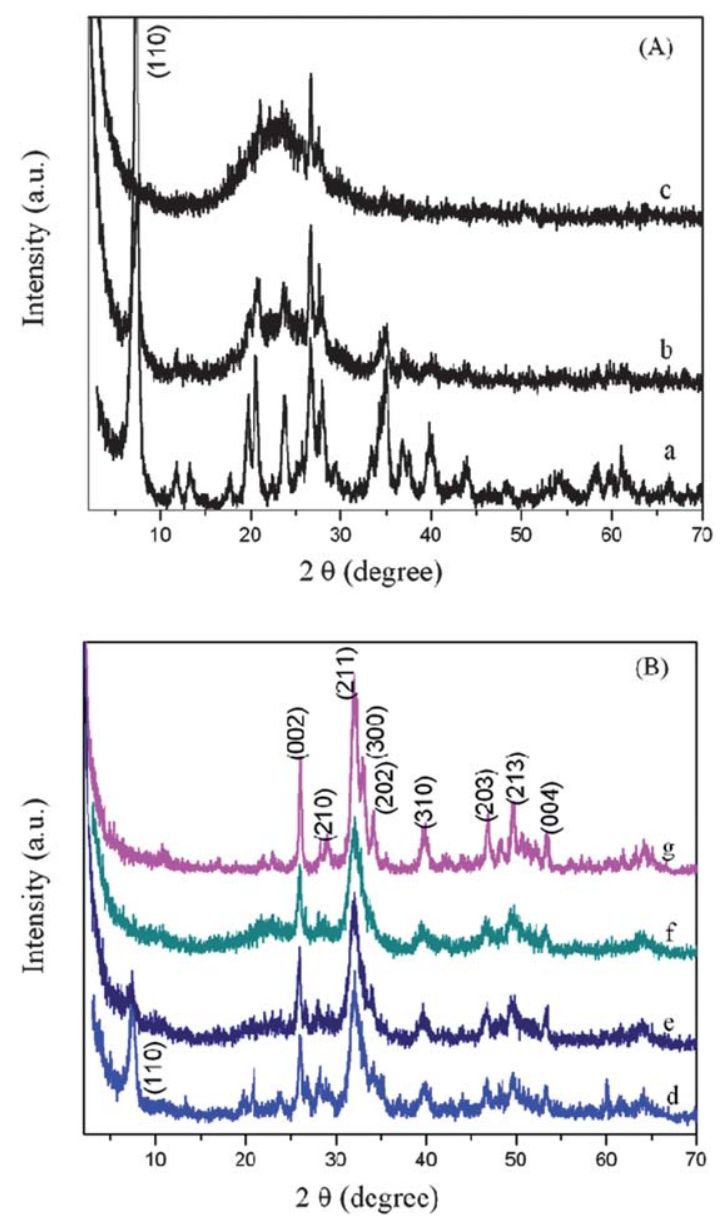

Fig. 3 XRD patterns of (A) the pristine sepiolite (a), Acid-SEP1 (b) and Acid-SEP2 (c); (B) HAp/SEP (d), HAp/Acid-SEP1 (e), HAp/Acid-SEP2 (f), and HAp (g). and the sepiolite has been converted to silica after the strong acid treatment. As a result, the typical fiber diameter of the sepiolite is reduced from $\sim 30$ to $\sim 5 \mathrm{~nm}$, the aspect ratio is increased from $\sim 20$ to 300 (Fig. $1 \mathrm{~b}$ and $\mathrm{d}$ ), and the specific surface area is increased from 148.2 to $452.5 \mathrm{~m}^{2} \mathrm{~g}^{-1}$ (Table 1). The increase of the specific surface area by $205 \%$ is in excellent agreement with the structural change experienced by the clay during the strong acid-treatment in which case a crystalline lattice consisting of two layers of silica and one layer of magnesia has become two crystalline lattices each consisting of one layer of silica only: the original lattice has a mass equivalent to about 3 times of the new single lattice yet gives the same surface area by neglecting the side surfaces because of the high aspect ratio of the lattice. The BJH pore volume and pore diameter were also found to increase by $59 \%$ and $99 \%$ (Table 1), respectively. Such acid-activated sepiolites with porous structure, high aspect ratio and high density of $\mathrm{SiOH}$ groups are expected to be more favorable for nucleation and growth of HAp crystallites as opposed to the pristine sepiolite.

\section{Characterization of nanocrystalline hydroxyapatites grown on the sepiolites}

In Fig. 2B (curve d), the HAp exhibits absorption bands at 562, $604,962,1024$ and $1090 \mathrm{~cm}^{-1}$ which are the characteristic peaks of $\mathrm{PO}_{4}{ }^{3-}$. The absorption band at $635 \mathrm{~cm}^{-1}$ belongs to librational bands of hydroxyl groups in HAp. The bands at $1416 \mathrm{~cm}^{-1}$ and $873 \mathrm{~cm}^{-1}$ are associated to the $\mathrm{C}-\mathrm{O}$ stretching vibration mode on the $\mathrm{CO}_{3}{ }^{2-}$ groups, which might be due to the dissolved $\mathrm{CO}_{2}$ from atmosphere during the reactions. ${ }^{20}$ The HAp/SEP and HAp/ Acid-SEP(1,2) samples exhibit absorption bands at 604 and $562 \mathrm{~cm}^{-1}$ corresponding to the $\mathrm{O}-\mathrm{P}-\mathrm{O}$ bending vibrations which are considered to originate from the $\mathrm{PO}_{4}{ }^{3-}$ groups in HAp crystals. The bands at 1094, 1025 and $961 \mathrm{~cm}^{-1}$ designated to $\mathrm{P}-\mathrm{O}$ stretching vibration modes partially overlapped with those for $\mathrm{Si}-\mathrm{O}$ groups because of the similarities of the $\mathrm{SiO}_{4}{ }^{4-}$ and $\mathrm{PO}_{4}{ }^{3-}$ tetrahedral units. ${ }^{20}$ As characterized by XRD (curve $\mathrm{g}$ in Fig. 3B), diffraction peaks at $2 \theta$ of $26.1^{\circ}, 32.2^{\circ}, 53.9^{\circ}$ and $64.7^{\circ}$ corresponding to HAp (JCPDS 09-0432) were observed, and no obvious traces of brushite (especially at $2 \theta=12^{\circ}$ and $21^{\circ}$ ) were identified, which means the synthesized HAp is pure. ${ }^{21}$ The characteristic diffraction peaks of HAp are visible for the HAp/ sepiolite samples. The above FT-IR and XRD results indicate that HAp has successfully grown on both pristine sepiolite and acid-activated sepiolites.

The average crystallite size $\left(D_{\mathrm{p}}\right)$ and crystallinity $\left(X_{\mathrm{c}}\right)$ of HAp/ SEP biocomposite calculated from the XRD traces, being 21.1

Table 1 BET surface area, micropore volume and pore diameter values of sepiolites, HAp and the related biocomposites

\begin{tabular}{llll}
\hline Sample & $\begin{array}{l}S_{\mathrm{BET}} / \mathrm{m}^{2} \\
\mathrm{~g}^{-1}\end{array}$ & $\begin{array}{l}\mathrm{BJH} \text { pore volume } / \mathrm{cm}^{3} \\
\mathrm{~g}^{-1}\end{array}$ & $\begin{array}{l}\mathrm{BJH} \text { pore diameter/ } \\
\mathrm{nm}\end{array}$ \\
\hline Sepiolite & 148.2 & 0.5722 & 7.9 \\
Acid-SEP2 & 452.5 & 0.9076 & 15.7 \\
HAp & 109.3 & 0.4272 & 3.4 \\
HAp/SEP & 145.7 & 0.6011 & 10.9 \\
HAp/Acid- & 182.0 & 0.7916 & 11.1 \\
$\quad$ SEP2 & & & \\
\hline
\end{tabular}


Table 2 Average crystallite sizes and crystallinities of HAp and HAp/ sepiolite biocomposites

\begin{tabular}{llll}
\hline Sample & $\begin{array}{l}\text { Line width } \\
(002) \text { FWHM}^{\circ}{ }^{\circ}\end{array}$ & $\begin{array}{l}\text { Average } \\
\text { crystallite } \\
\text { size }(002), D_{\mathrm{p}} / \mathrm{nm}\end{array}$ & $\begin{array}{l}\text { Crystallinity, } \\
X_{\mathrm{c}}(\%)\end{array}$ \\
\hline HAp & 0.308 & 27.6 & 47.2 \\
HAp/SEP & 0.405 & 21.1 & 20.9 \\
HAp/Acid- & 0.391 & 21.8 & 23.1 \\
$\quad$ SEP1 & 0.375 & 22.7 & 26.3 \\
HAp/Acid- & & & \\
$\quad$ SEP2 & & & \\
\hline
\end{tabular}

nm and $20.9 \%$, respectively, are lower than those of HAp being $27.6 \mathrm{~nm}$ and $47.2 \%$ (Table 2). Low-crystallinity apatites are preferred in biomedical and tissue engineering applications due to their high 'in vivo' resorbability rate. ${ }^{22}$ The $D_{\mathrm{p}}$ of HAp/SEP does not show much difference as compared to those of HAp/ Acid-SEP samples, but its $X_{\mathrm{c}}$ is slightly lower, which may be attributed to the more $\mathrm{Si}-\mathrm{OH}$ groups present in the latter acting as the nucleation sites. The $D_{\mathrm{p}}$ and $X_{\mathrm{c}}$ values of the HAp/sepiolite biocomposites are comparable to those of HAp nanocrystals synthesized by using chitosan as the template ${ }^{21}$ and those of biological apatites. ${ }^{22}$

The BET specific surface areas of the HAp/SEP and HAp/ Acid-SEP2 are considerably higher than that of the HAp nanocrystals synthesized without sepiolite, being $145.7 \mathrm{~m}^{2} \mathrm{~g}^{-1}$ and $182.0 \mathrm{~m}^{2} \mathrm{~g}^{-1}$ versus $109.3 \mathrm{~m}^{2} \mathrm{~g}^{-1}$ (Table 1). These suggest the HA/ sepiolite composites would provide larger interfacial surfaces for manipulating their interactions with surroundings when compared to the unfilled HAp. As observed with TEM, the HAp nanocrystals are needle-like of $c a .10 \times 100 \mathrm{~nm}$ in size (Fig. $4 \mathrm{c}$ ).
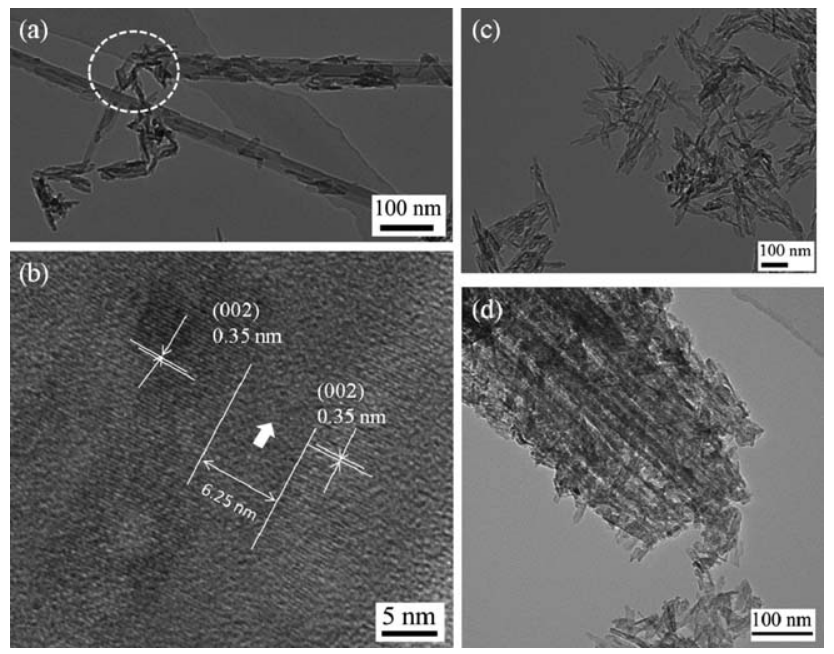

Fig. 4 TEM images illustrating HAp formation on the sepiolites: (a) HAp/SEP biocomposite, the circled part shows the broken sepiolite surface (defects) also acts as nucleation sites for HAp nanoparticles growth; (b) high magnification image of the HAp nanocrystals showing $0.35 \mathrm{~nm}$ lattice-fringe separations in the HAp/SEP sample, the arrow indicates the distance between the two HAp crystals on the sepiolite surface, which is $6.25 \mathrm{~nm}$ in this case; (c) HAp particles synthesized in the same condition as that of HAp/SEP sample; (d) HAp/Acid-SEP2 biocomposite.
In comparison, the morphology of HAp in HAp/SEP biocomposite (Fig. 4a) is in nanorod-shape with $20-60 \mathrm{~nm}$ in length and $10-20 \mathrm{~nm}$ in width. The nanorods grew from the external channels and oriented to the $c$-axis of sepiolite fibers, with some growing along the broken surfaces (defects). A HAp lattice plane of $0.35 \mathrm{~nm}$ corresponding to the (002) plane was clearly identified in the TEM image (Fig. 4b). A $6.25 \mathrm{~nm}$-wide zone with a different crystalline structure in between the two HAp nanocrystals was also observed. The amount of HAp on the sepiolite surface was estimated as $31 \mathrm{wt} \%$ based on the TGA results by comparing the weight losses of HAp, sepiolite and HAp/SEP composite in the range of $300-600{ }^{\circ} \mathrm{C}$ (Fig. S1†). As shown in Fig. 4d, more HAp crystals grew inside Acid-SEP2 textures and interconnected closely with the silica fibers, indicating that the size and amount of HAp nanocrystals directly correlate with the amount of $\mathrm{Si}-\mathrm{OH}$ groups (nucleation sites) in sepiolites. The amount of HAp crystals on the Acid-SEP2 structures was estimated as $67 \mathrm{wt} \%$ based on the TGA results, similar to the value estimated from the XRF result by considering the contents of $\mathrm{CaO}$ in Acid-SEP2, HAp and HAp/AcidSEP2 (Table S1 $\dagger$ ), being $65 \mathrm{wt} \%$. So, the average ratio of HAp to the Acid-SEP2 $(1.94: 1)$ is around the initial feed ratio $(2: 1)$ indicating the nucleation and growth of HAp crystals mainly occurred on the Acid-SEP2 fibers. The estimated amount of HAp in the Acid-SEP1 is $48 \mathrm{wt} \%$, which is in between the values for HAp/SEP and HAp/Acid-SEP2 biocomposites. Therefore, the acid-activated sepiolite is more favorable for the nucleation and growth of HAp nanocrystals due to the presence of more $\mathrm{Si}-\mathrm{OH}$ functional groups acting as nucleation sites, a larger specific surface and more mesopores acting as growth templates.

Based on the above analysis, the nucleation mechanism of HAp on sepiolite and acid-activated sepiolites is proposed as follows. The initial $\mathrm{Si}-\mathrm{OH}$ groups on the edge of surface channels and some pore defects in the pristine sepiolite may absorb $\mathrm{Ca}^{2+}$ ions through electrostatic interactions and act as nucleation sites for HAp formation. In comparison, the abundant $\mathrm{Si}-\mathrm{OH}$ groups on the acid-activated sepiolite surface, i.e. the freshly exfoliated silicate fibers, are expected to attract even more $\mathrm{Ca}^{2+}$ ions into the mesopores of sepiolites through an inter-diffusion process. Moreover, some $\mathrm{Ca}^{2+}$ ions could enter into the octahedral positions originally occupied by $\mathrm{Mg}^{2+}$ which were lixiviated under strong acid attack, thus creating local supersaturation of $\mathrm{Ca}^{2+}$ ions in the channels and around the silica fibers, and facilitate nucleation and growth of HAp nanocrystals on the sepiolite templates.

\section{Nucleation of crystalline hydroxyapatites in the presence of sepiolite}

According to the classical nucleation theory, the driving force for a small nucleus to overcome a nucleation barrier and become a stable growing crystal in the solution is the change in Gibbs free energy. For a homogenous nucleation process, the total Gibbs free energy $\Delta G_{\text {homo }}$ for the formation of a spherical crystallite with radius $r$ is expressed as eqn (4), ${ }^{23,24}$

$$
\Delta G_{\mathrm{homo}}=\frac{4}{3} \pi r^{3} \Delta \mu+4 \pi r^{2} \gamma_{\mathrm{cf}}
$$


where $\Delta \mu$ is the change of specific free energy associated with the liquid-solid phase change, $\gamma_{\mathrm{cf}}$ is the crystal-solution interfacial tension per unit surface area $\left(\mathrm{mJ} \mathrm{m}^{-2}\right)$.

In the presence of sepiolite, nucleation of HAp crystallites takes place in a heterogeneous way, and the nucleation barrier is reduced to, ${ }^{24 a}$

$$
\Delta G_{\text {het }}=f\left(m, R^{\prime}\right) \Delta G_{\text {homo }}\left[0 \leq f\left(m, R^{\prime}\right) \leq 1\right]
$$

where $f\left(m, R^{\prime}\right)$ is the interfacial correlation factor varying from 0 to $1 ; m=\left(\gamma_{\mathrm{sf}}-\gamma_{\mathrm{sc}}\right) / \gamma_{\mathrm{cf}} \approx \cos \alpha, \alpha$ is the contact angle between the liquid and solid, $\gamma_{\mathrm{sf}}, \gamma_{\mathrm{cf}}$ and $\gamma_{\mathrm{sc}}$ are the interfacial tensions per unit surface area for the sepiolite-solution, crystal-solution and sepiolite-crystal; $R^{\prime}=R^{\mathrm{s}} / r_{\mathrm{c}}$, namely the dimensionless radius of curvature of the substrate $\left(R^{\mathrm{s}}\right)$ with reference to the radius of critical nuclei. ${ }^{24 a}$

Assuming the sepiolite is a flat substrate, $R^{\mathrm{s}} \rightarrow \infty, R^{\prime} \rightarrow \infty$, so $f\left(m, R^{\prime}\right)=f(m)$ which is only dependent on $m,{ }^{24 a}$ thus:

$$
f\left(m, R^{\prime}\right)=\frac{(2+m)(1-m)^{2}}{4} \approx \frac{(2+\cos \alpha)(1-\cos \alpha)^{2}}{4}
$$

The interfacial tension $\gamma_{i j}$ between phases $i$ and $j$ is obtained using the van Oss-Chaudhury-Good equation, ${ }^{23 a}$

$$
\begin{aligned}
\gamma_{i j}= & \left(\sqrt{\gamma_{i}^{\mathrm{LW}}}-\sqrt{\gamma_{j}^{\mathrm{LW}}}\right)^{2}+2\left(\sqrt{\gamma_{i}^{\oplus} \gamma_{i}^{\ominus}}+\sqrt{\gamma_{j}^{\oplus} \gamma_{j}^{\ominus}}-\sqrt{\gamma_{i}^{\oplus} \gamma_{j}^{\ominus}}\right. \\
& \left.-\sqrt{\gamma_{j}^{\oplus} \gamma_{i}^{\ominus}}\right)
\end{aligned}
$$

in which $\gamma^{\mathrm{LW}}$ is the Lifshitz-van der Waals surface tension component, $\gamma^{\oplus}$ and $\gamma^{\odot}$ are the Lewis acid and Lewis base parameters, respectively, which can be calculated from contact angles.

According to the surface tension components cited from the literature as shown in Table 3 , the $\gamma_{\mathrm{sf}}, \gamma_{\mathrm{cf}}$ and $\gamma_{\mathrm{sc}}$ were calculated as $9.75,9.06$, and $0.17 \mathrm{~mJ} \mathrm{~m}^{-2}$, respectively. Then $m \rightarrow 1, \alpha \approx 0^{\circ}$, $f(m) \rightarrow 0$, which means both a strong interaction and an optimal structural match occur between the substrate (sepiolite) and the nucleating phase (HAp); the heterogeneous nucleation is kinetically favored. ${ }^{23 a, 24}$ Nucleation of HAp crystallites tends to be templated by sepiolite having an excellent structural correlation with the crystalline phase of HAp.

The heterogeneous critical nucleus size $r_{\mathrm{c}}{ }^{\prime}$ is obtained by evaluating from $\left(\partial \Delta G_{\text {het }} / \partial r\right)=0$, so

$$
r_{\mathrm{c}}^{\prime}=\frac{2 \gamma_{\mathrm{cf}} \nu}{\Delta \mu}=\frac{2 \gamma_{\mathrm{cf}} \nu}{k T \ln \Omega}
$$

in which $v$ is the effective volume of unit cell of the HAp crystal, i.e. $0.529 \mathrm{~nm}^{3},{ }^{23 a} k$ is the Boltzmann constant, $1.38 \times 10^{-23} \mathrm{~J} \mathrm{~K}^{-1}$;

Table 3 Surface tension components of various materials cited from the literature and the calculated values of interfacial free energy $\left(\mathrm{mJ} \mathrm{m}^{-2}\right)$

\begin{tabular}{llllll}
\hline Sample & $\begin{array}{l}\gamma^{\mathrm{LW} / \mathrm{mJ}} \\
\mathrm{m}^{-2}\end{array}$ & $\begin{array}{l}\gamma^{\oplus} / \mathrm{mJ} \\
\mathrm{m}^{-2}\end{array}$ & $\begin{array}{l}\gamma^{\oplus / \mathrm{mJ}} \\
\mathrm{m}^{-2}\end{array}$ & Ref. & $\begin{array}{l}\text { Calculated } \\
\gamma_{i j} / \mathrm{mJ} \mathrm{m}^{-2}\end{array}$ \\
\hline Water & 21.8 & 25.5 & 25.5 & 23 & - \\
HAp & 28.5 & 0.9 & 16.0 & 23 & $\gamma_{\mathrm{cf}}=9.06$ \\
Sepiolite & 35.0 & 0.2 & 17.3 & 30 & $\gamma_{\mathrm{sf}}=9.75$ \\
\hline
\end{tabular}

$T$ is the absolute temperature, $323 \mathrm{~K} ; \Omega$ is the supersaturation ratio, $\Omega=\left(\mathrm{IAP} / K_{\mathrm{sp}}\right)^{1 / 9}$, in which IAP is the initial ionic activity product and $K_{\mathrm{sp}}$ is the solubility product. In this work, the feeding solution contained $0.5 \mathrm{M}$ of $\mathrm{Ca}^{2+}$ and $0.3 \mathrm{M}$ of $\mathrm{PO}_{4}{ }^{3-}$, the IAP value was therefore calculated ${ }^{25 a}$ as $1.83 \times 10^{-32}$. The solubility of calcium phosphates $K_{\mathrm{sp}}$ generally decreases as the temperature increases, for example $2.35 \times 10^{-59}$ at $37^{\circ} \mathrm{C}^{25 b}$ and $7.3 \times 10^{-61}$ at $85^{\circ} \mathrm{C}^{25 a}$ So the $K_{\mathrm{sp}}$ at $50^{\circ} \mathrm{C}$ should be in the range of $2.35 \times 10^{-59}$ to $7.3 \times 10^{-61} \cdot{ }^{25 c, d}$ Correspondingly, $\ln \Omega$ was determined to be in the range of 6.88-7.27.

From eqn (8), the critical nucleus size of $r_{\mathrm{c}}{ }^{\prime}$ is dependent on the interfacial tension and supersaturation. The interfacial tension of HAp, $\gamma_{\mathrm{cf}}$, has been determined by different methods including crystal growth and dissolution kinetics as well as contact angle measurements as reviewed by $\mathrm{Wu}$ and Nancollas. ${ }^{23 a}$ The $\gamma_{\mathrm{cf}}$ values determined by the kinetics method vary from $9.3-120 \mathrm{~mJ}$ $\mathrm{m}^{-2}$ in the literature because the kinetics method involves a number of variables that are challenging to measure experimentally. ${ }^{23 a}$ In comparison, the contact angle measurement gives more consistent results and $10 \mathrm{~mJ} \mathrm{~m}^{-2}$ was determined for the $\gamma_{\mathrm{cf}}$ by contact angle methods. ${ }^{23 a}$ In our case, the $\gamma_{\mathrm{cf}}$ value was calculated as $9.06 \mathrm{~mJ} \mathrm{~m}^{-2}$ as previously discussed, which is in the same order of the measured data, $10 \mathrm{~mJ} \mathrm{~m}^{-2}$. Based on the estimated $\ln \Omega$ values, eqn (8) and the data in Table 3 , the $r_{\mathrm{c}}{ }^{\prime}$ is estimated to be $0.296-0.312 \mathrm{~nm}$, thus the molecular volume of the unit cell of crystal is $1.867-2.187 \mathrm{~nm}^{3}$ given that nine molecules form one HAp unit cell.

The $r_{\mathrm{c}}{ }^{\prime}$ estimated in this study is in the same order of the reported data, varying from 0.28 to $0.72 \mathrm{~nm} \cdot{ }^{25-27}$ It is difficult to calculate the exact size and distribution of the tremendous numbers of nuclei in the presence of sepiolites since the nature and size of the nuclei change rapidly which induces the change of interfacial energy and residual supersaturation when precipitation occurs. However, the values of $r_{\mathrm{c}}{ }^{\prime}$ calculated based on the data in the literature would reflect the crystallization nature of HAp in the presence of sepiolites. As aforementioned, the acidactivated sepiolites provide more nucleation sites for HAp growth compared to the pristine sepiolite, so the size of critical nuclei of HAp in the presence of acid-activated sepiolites is speculated to be smaller than in the case with the pristine sepiolite.

\section{Mechanical properties of calcinated HAp/sepiolite biocomposites}

Elastic modulus and hardness of sepiolites and HAp calcinated at $1200{ }^{\circ} \mathrm{C}$ were measured by nanoindentation. The typical loaddisplacement curves and the results are shown in Fig. S2 $\uparrow$ and Table 4, respectively.

The elastic modulus of sepiolite is $10.58 \mathrm{GPa}$, much lower than the theoretical elastic modulus of smectite clay platelets without gallery spacing, namely about $230 \mathrm{GPa},{ }^{16 b}$ due to the structural tunnels and pore defects present throughout the sepiolite textures. Vanorio et al. ${ }^{28 a}$ found the Young's modulus values for bulk montmorillonite and other smectite clay minerals were between 9.8 and $15.4 \mathrm{GPa}$ by extrapolation of acoustic measurements on cold-pressed samples having different porosities, which are similar to those obtained with atomic force acoustic microscopy for dickite by Prasad et al., ${ }^{28 b}$ i.e. $6.2 \mathrm{GPa}$. The elastic modulus of sepiolite measured by nanoindentation in 
Table 4 Physical and mechanical properties of sepiolites and HAp

\begin{tabular}{|c|c|c|c|}
\hline Sample code & $\begin{array}{l}\text { Elastic modulus }{ }^{a} \\
\mathrm{GPa}\end{array}$ & $\begin{array}{l}\text { Hardness }{ }^{a} / \\
\mathrm{GPa}\end{array}$ & $\begin{array}{l}\text { Specific } \text { gravity }^{b} / \\
\mathrm{g} \mathrm{cm}^{-3}\end{array}$ \\
\hline & $10.58 \pm 0.22$ & $1.31 \pm 0.04$ & 2.38 \\
\hline Acid-SEP1 & $35.31 \pm 2.19$ & $3.75 \pm 0.02$ & 2.09 \\
\hline Acid-SEP2 & $41.83 \pm 3.51$ & $5.91 \pm 0.01$ & 1.98 \\
\hline HAp & $19.33 \pm 0.05$ & $1.69 \pm 0.02$ & 2.92 \\
\hline
\end{tabular}

${ }^{a}$ The elastic moduli and hardness of the samples were measured by a nanoindenter and calculated with Oliver-Pharr method. ${ }^{15 a}{ }^{b}$ The specific gravity values were measured by helium pycnometry.

this study is comparable to the literature data for bulk clays with gallery spacing. As presented in Table 4, the elastic modulus values of acid-activated sepiolites were higher than that of sepiolite, especially for the Acid-SEP2 with a $295 \%$ increase. This may be mainly explained as that the lixiviation of magnesium layers during the acid treatment has caused the sepiolite fibers to transform into silica fibers. However, the elastic modulus and density of Acid-SEP2, i.e. $41.83 \mathrm{GPa}$ and $1.98 \mathrm{~g} \mathrm{~cm}^{-3}$, are lower than those of fused silica, $73 \mathrm{GPa}$ and $2.2 \mathrm{~g} \mathrm{~cm}^{-3},{ }^{15 c}$ respectively, suggesting the resultant silica fibers still have some structural defects (pores) and channels on the surface. Similar to modulus, the hardness values of acid-activated sepiolites were also higher than that of sepiolite. The elastic modulus and hardness of HAp were $19.33 \mathrm{GPa}$ and $1.69 \mathrm{GPa}$, respectively, lower than those of the acid-activated sepiolites, while the density is substantially higher (Table 4, column 3).

Based on the experimental results given in Table 4 and the assumption that the HAp nanocrystals only grow on the fiber surfaces, the elastic modulus for the HAp/Acid-SEP2 biocomposite was predicted using Halpin-Tsai model, ${ }^{29}$

$$
E_{\mathrm{c}}=E_{\mathrm{m}} \frac{(1+\xi \eta \phi)}{(1-\eta \phi)}
$$

where $E$ is the modulus of the materials and subscripts c and $\mathrm{m}$ refer to the composite and the matrix, respectively; $\phi$ is the volume fraction of the fibers and $\eta$ is a function of the moduli of fibers and matrix ( $E_{\mathrm{f}}$ and $E_{\mathrm{m}}$, respectively) and is defined as $\eta=$ $\left(E_{\mathrm{f}} / E_{\mathrm{m}}-1\right) /\left(E_{\mathrm{f}} / E_{\mathrm{m}}+\xi\right), \xi$ is the shape factor, $\xi=2(l / t)$ where $l / t$ represents the aspect ratio of the fibers.

The calculated elastic modulus of HAp/Acid-SEP2 biocomposite is $29.03 \mathrm{GPa}, 50 \%$ higher than that of HAp. The actual modulus of such composite is expected to be even higher because the HAp nanocrystals grow interconnecting with the fibers, existing both in the pore defects and the surface of the fibers as discussed above.

\section{Conclusions}

The natural fibrous sepiolite has been proven to be an effective inorganic host for HAp mineralization. Carbonated HAp nanorods with dimensions of 20-60 nm in length and 10-20 nm in width were observed to grow on the sepiolite surfaces with a preferred orientation to the $c$-axis. The critical nucleus radius of HAp in the presence of natural sepiolite was estimated as $0.296-$ $0.312 \mathrm{~nm}$ which provides the evidence that the nucleation of HAp only occurs from the external channels and pore defects in the sepiolite, but not from the structural tunnels. Strong acidactivation increased the specific surface area of the sepiolite by $205 \%$, and provided many more silanol groups on the fiber surfaces, facilitating formation of uniform and thick layers of HAp nanocrystallites on the surfaces. The novel HAp/AcidSEP2 biocomposite developed has a specific surface area of $182 \mathrm{~m}^{2} \mathrm{~g}^{-1}$, an elastic modulus of over $20 \mathrm{GPa}$, and similar biological functions to HAp because of the full coverage of HAp nanocrystallites on the silica surfaces. This class of new biocomposites is considered to be promising in tissue engineering and medical fields.

\section{Acknowledgements}

This research was supported by a Marie Curie International Incoming Fellowship within the $7^{\text {th }}$ European Community Framework Programme under Grant Agreement No. PIIF-GA2009-236739. C.W. also thanks funding from National Natural Science Foundation of China (Project No. 50803035).

\section{References}

1 (a) C. Sanchez, H. Arribart and M. M. G. Guille, Nat. Mater., 2005, 4, 277; (b) S. Mann, in Biomineralization: Principles and Concepts in Bioinorganic Materials Chemistry, Oxford University Press, Oxford, 2001.

2 R. J. Narayan, P. N. Kumta, C. Sfeir, D. H. Lee, D. Choi and D. Olton, JOM, 2004, 56, 38.

3 (a) S. Weiner and H. D. Wagner, Annu. Rev. Mater. Sci., 1998, 28, 271; (b) J. D. Currey, Science, 2005, 309, 253.

4 (a) Y. Cai and R. K. Tang, J. Mater. Chem., 2008, 18, 3775; (b) Y. Cai, Y. K. Liu, W. Q. Yan, Q. H. Hu, J. H. Tao, M. Zhang, Z. L. Shi and R. K. Tang, J. Mater. Chem., 2007, 17, 3780; (c) S. Bose and S. K. Saha, Chem. Mater., 2003, 15, 4464; (d) T. J. Webster, C. Ergun, R. H. Doremus, R. W. Siegel and R. Bizios, Biomaterials, 2001, 22, 1327; (e) E. S. Thian, J. Huang, S. M. Best, Z. H. Barber, R. A. Brooks, N. Rushton and W. Bonfield, Biomaterials, 2006, 27, 2692.

5 A. L. Wang, D. Liu, H. B. Yin, H. X. Wu, Y. J. Wada, M. Ren, T. S. Jiang, X. N. Cheng and Y. Q. Xu, Mater. Sci. Eng., C, 2007, 27, 865 .

6 (a) S. H. Oh, R. R. Finones, C. Daraio, L. H. Chen and S. H. Jin, Biomaterials, 2005, 26, 4938; (b) H. Tsuchiya, J. M. Macak, L. Müller, J. Kunze, F. Müller, P. Greil, S. Virtanen and P. Schmuki, J. Biomed. Mater. Res., Part A, 2006, 77, 534.

7 (a) B. Zhao, H. Hu, S. K. Mandal and R. C. Haddon, Chem. Mater., 2005, 17, 3235; (b) S. Liao, G. F. Xu, W. Wang, F. Watari, F. Z. Cui, S. Ramakrishna and C. K. Chan, Acta Biomater., 2007, 3, 669; (c) S. Aryal, K. C. Remant Bahadur, N. Dharmaraj, K. W. Kim and H. Y. Kim, Scr. Mater., 2006, 54, 131; (d) Y. Xiao, T. Gong and S. B. Zhou, Biomaterials, 2010, 31, 5182.

8 (a) M. Iafisco, M. Marchetti, J. G. Morales, M. A. HernandezHernandez, J. M. G. Ruiz and N. Roveri, Cryst. Growth Des., 2009, 9, 4912; (b) N. Sahai and J. A. Tossell, J. Phys. Chem. B, 2000, 104, 4322; (c) M. M. Walker, MS thesis, University of Florida, 1977; (d) M. M. Pereira and L. L. Hench, J. Sol-Gel Sci. Technol., 1996, 7, 59; (e) Y. Deng, X. K. Li and Q. Li, Ind. Eng. Chem. Res., 2009, 48, 8829; $(f)$ H. Yan, K. Zhang, C. F. Blanford, L. F. Francis and A. Stein, Chem. Mater., 2001, 13, 1374.

9 D. Rautaray, S. Mandal and M. Sastry, Langmuir, 2005, 21, 5185.

10 (a) P. Aranda, R. Kun, M. A. Martín-Luengo, S. Letaïef, I. Dékány and E. Ruiz-Hitzky, Chem. Mater., 2008, 20, 84; (b) J. Santaren, J. Sanz and E. Ruiz-Hitzky, Clays Clay Miner., 1990, 38, 63; (c) M. Rautureau and A. Mifsud, Clay Miner., 1977, 12, 309; (d) J. L. Ahlrichs, J. C. Serna and J. M. Serratosa, Clays Clay Miner., 1975, 23, 119; (e) S. Balci, J. Chem. Technol. Biotechnol., 1996, 66, 72. 11 J. H. Choy, S. J. Choi, J. M. Oh and T. Park, Appl. Clay Sci., 2007, 36, 122. 
12 V. Vergaro, E. Abdullayev, Y. M. Lvov, A. Zeitoun, R. Cingolani, R. Rinaldi and S. Leporatti, Biomacromolecules, 2010, 11, 820.

13 V. P. Cerezo, R. Sanchez, I. Salcedo and C. Aguzzi, Appl. Clay Sci., 2010, 48, 291.

14 (a) B. D. Culity, in Elements of X-Ray Diffraction, Addison-Wesley, Reading, MA, 1978; (b) E. Landi, A. Tampieri, G. Celotti and S. Sprio, J. Eur. Ceram. Soc., 2000, 20, 2377.

15 (a) W. C. Oliver and G. M. Pharr, J. Mater. Res., 2004, 19, 3; (b) N. A. Sakharova, J. V. Fernandes, J. M. Antunes and M. C. Oliveira, Int. J. Solids Struct., 2009, 46, 1095; (c) C. P. Wong and R. S. Bollampally, J. Appl. Polym. Sci., 1999, 74, 3396.

16 (a) B. Chen and J. R. G. Evans, Macromolecules, 2006, 39, 747; (b) B. Chen and J. R. G. Evans, Scr. Mater., 2006, 54, 1581; (c) M. Akao, H. Aoki and K. Kato, J. Mater. Sci., 1981, 16, 809.

17 (a) J. D. Russell, Infrared Methods, in Handbook of Determinative Methods in Clay Mineralogy, ed. M. J. Wilson, Chapman \& Hall, New York, 1987; (b) R. L. Frost, O. B. Locos, H. Ruan and J. T. Kloprogge, Vib. Spectrosc., 2001, 27, 1; (c) J. Cornejo and M. C. Hermosin, Clay Miner., 1988, 23, 391; (d) J. L. Vallentin., M. A. Lopez-Manchado, A. Rodriguez, P. Posadas and L. Ibarra, Appl. Clay Sci., 2007, 36, 245; (e) H. H. W. Moenke, in Infrared Spectra of Minerals, ed. V. C. Farmer, Mineralogical Society, London, UK, 1974, p. 365.

18 (a) M. A. Vicente-Rodríguez, M. Suarez, M. A. Bañares-Muñoz and J. D. D. Lopez-Gonzalez, Spectrochim. Acta, Part A, 1996, 52, 1685; (b) P. Komadel, in Natural Microporous Materials in Environmental Technology, ed. P. Misaelides, Kluwer Academic Publishers, Dordrecht, The Netherlands, 1999, p. 3.
19 A. Choudhury, A. K. Bhowmick and C. Ong, Polymer, 2009, 50, 201.

20 Y. Kuwahara, T. Ohmichi, T. Kamegawa, K. Mori and H. Yamashita, J. Mater. Chem., 2009, 19, 7263.

21 V. M. Rusu, C. H. Ng, M. Wilke, B. Tiersch, P. Fratzl and M. G. Peter, Biomaterials, 2005, 26, 5414.

22 S. V. Dorozhkin and M. Epple, Angew. Chem., Int. Ed., 2002, 41, 3130.

23 (a) W. J. Wu and G. H. Nancollas, Adv. Colloid Interface Sci., 1999, 79, 229; (b) W. J. Wu and G. H. Nancollas, J. Colloid Interface Sci., 1996, 182, 365.

24 (a) X. Y. Liu and S. W. Lim, J. Am. Chem. Soc., 2003, 125, 888; (b) J. M. Ha, J. H. Wolf, M. A. Hillmyer and M. D. Ward, J. Am. Chem. Soc., 2004, 126, 3382.

25 (a) R. Rodríguez-Clemente, A. López-Macipe, J. Gómez-Morales, J. Torrent-Burgués and V. M. Castaño, J. Eur. Ceram. Soc., 1998, 18, 1351; (b) H. McDowel, T. M. Gregory and W. E. Brown, J. Res. Natl. Bur. Stand., Sect. A, 1977, 81, 273; (c) J. S. Clark, Can. J. Chem., 1955, 285, 1696; (d) R. Kumar, K. H. Prakash, P. Cheang and K. A. Khor, Langmuir, 2004, 20, 5196.

26 J. Christoffersen and M. R. Christoffersen, J. Cryst. Growth, 1992, 121, 608 .

27 K. Onuma and A. Ito, Chem. Mater., 1998, 10, 3346.

28 (a) T. Vanorio, M. Prasad and A. Nur, Geophys. J. Int., 2003, 155, 319; (b) M. Prasad, M. Kopycinska, U. Rabe and W. Arnold, Geophys. Res. Lett., 2002, 29, 8.

29 J. C. Halpin and S. W. Tsai, AFML-TR-67-423, 1969.

30 Z. Li, PhD thesis, The State University of New York, Buffalo, 1993. 